\title{
Splenic artery aneurysm bleeding via the ampulla of Vater
}

Finding the cause of obscure-overt gastrointestinal (GI) bleeding is often a difficult and time-consuming process. Despite extensive research, up to $20 \%$ of patients remain undiagnosed $[1,2]$. We present the case of a 74-year-old man with a history of acute pancreatitis, who was hospitalized several times in district hospitals for hemodynamically significant, recurrent, GI bleeding.

The patient required transfusion of 46 units of packed-red blood cells and 16 units of fresh frozen plasma in total (the lowest hemoglobin level was $5.4 \mathrm{~g} / \mathrm{dL}$ ) over a period of 5 months. Multiple endoscopic examinations revealed the presence of hematin and frank blood and/or clots in the upper and lower GI tracts, but the exact bleeding source remained unknown.

Computed tomography showed a pancreatic tail pseudocyst and a splenic artery aneurysm ( $\bullet$ Fig. 1). Technetium-labeled red blood cell scintigraphy confirmed a focus of increased radiotracer activity in the left upper GI quadrant ( $\bullet$ Fig. 2).

Duodenoscopy was performed, during which a blood clot and fresh blood could be seen flowing from the ampulla of Vater ( $\bullet$ Fig. 3, Video 1 ). The patient was diagnosed with an aneurysm that was bleeding into the pancreatic cyst, with periodic evacuation of blood via the pancreatic duct into the lumen of the GI

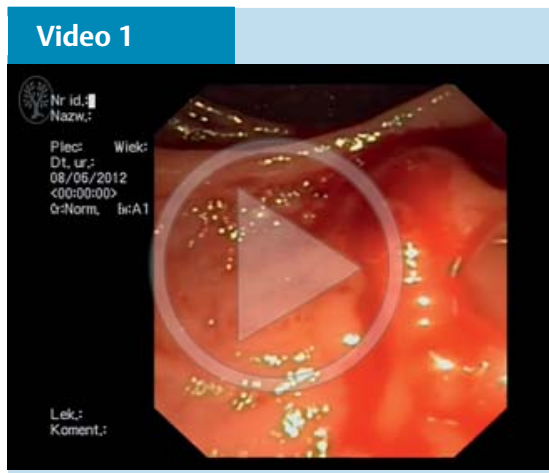

Duodenoscopy performed during hemodynamically significant active gastrointestinal bleeding revealed source of bleeding - a large volume of fresh blood and a few clots were flowing from the ampulla of Vater.

tract. Emergency selective celiacography was unsuccessful due to the sharp angulation of the splenic artery ( Fig.4); thus, a surgical splenopancreatectomy
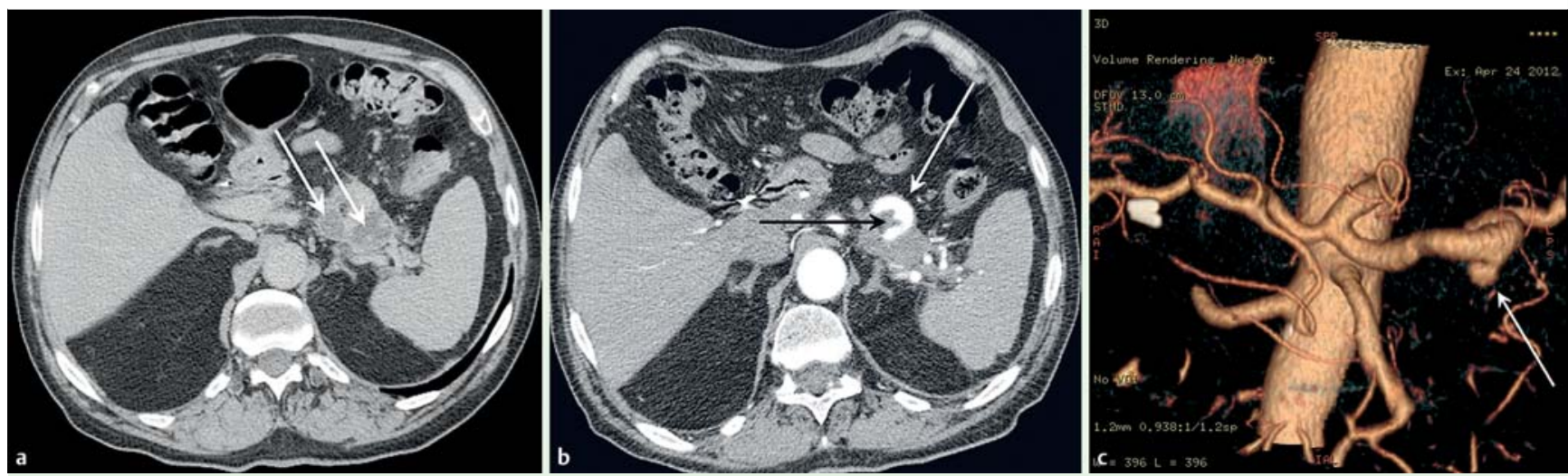

Fig. 1 Computed tomography (CT) images. a Contrast-enhanced, multidetector, multiphase $\mathrm{CT}$ of the abdomen and pelvis showing chronic pancreatitis, with cysts in the tail $(\varnothing 48 \times 28 \mathrm{~mm})$ and corpus $(\varnothing 41 \times 11 \mathrm{~mm})$ of the pancreas (arrows). b Angio-CT showing aneurysm of the splenic artery (in chronic pancreatitis), $9 \times 9 \times 12 \mathrm{~mm}$ size (neck of the aneurysm $5 \mathrm{~mm}$ [black arrow]). The splenic artery was also irregular and angulated (white arrow). c Angio-reconstruction of angio-CT performed during active bleeding, showing splenic artery aneurysm (arrow) with radiological suggestion of blood extravasation to the pseudocyst.
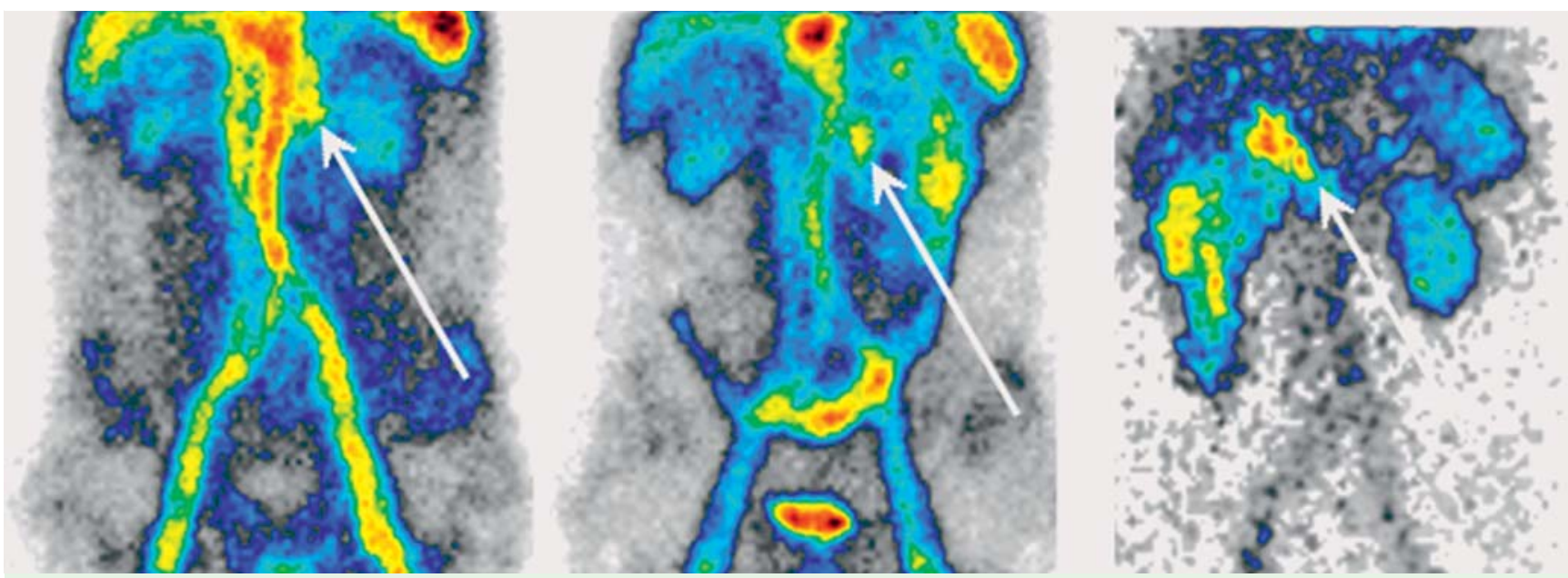

Fig. 2 Scintigraphy showing a focus of increased radiotracer activity in the left upper gastrointestinal quadrant (arrows), even after 24 hours. 


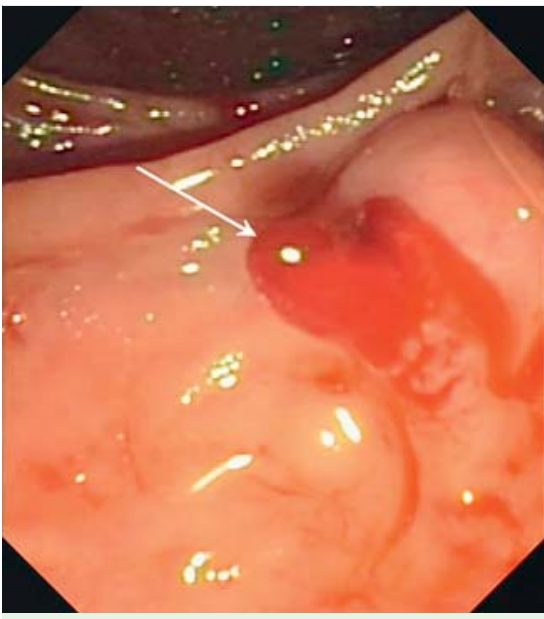

Fig. 3 Duodenoscopy revealed a clot outflow from the ampulla of Vater (arrow).

was performed. After 3 years of followup, the patient remains cured.

In summary, rare but potentially lifethreatening bleeding from aneurysms of the visceral arteries should be suspected, especially in patients with a history of pancreatitis. Repeating endoscopic examinations may visualize atypical, unusual bleeding sources in difficult cases.

Endoscopy_UCTN_Code_CCL_1AZ_2AO

Competing interests: None

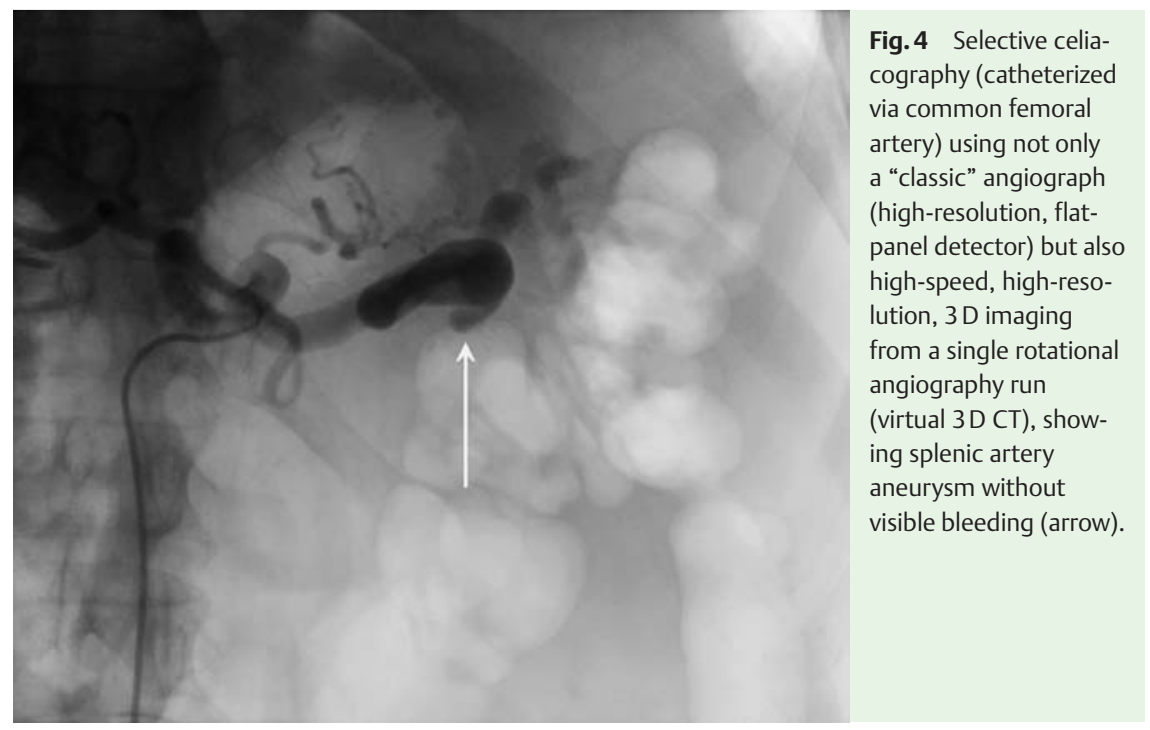

Anna Pietrzak ${ }^{1,2}$, Tomasz Olesiński², Jarosław Reguła', ${ }^{1,2}$, Edyta Zagórowicz ${ }^{1,2}$, Jakub Pałucki², Andrzej Mróz ${ }^{2}$

${ }^{1}$ Department of Gastroenterology, Hepatology and Clinical Oncology, Medical Centre for Postgraduate Education, Warsaw, Poland

${ }^{2}$ Maria Sklodowska-Curie Memorial Cancer Center, Institute of Oncology, Warsaw, Poland

\section{References}

1 Rondonotti E, Marmo R, Petracchini $M$ et al. The American Society of Gastrointestinal Endoscopy (ASGE) diagnostic algorithm for obscure gastrointestinal bleeding. Eight burning questions from everyday practice. Dig Liver Dis 2013; 45: 179-185

2 Fisher L, Lee Krinsky M, Anderson MA et al. The role of endoscopy in the management of obscure bleeding. Gastrointest Endosc 2010; 72: 471-479
Bibliography

DOI http://dx.doi.org/

10.1055/s-0034-1392604

Endoscopy 2015; 47: E421-E422

(c) Georg Thieme Verlag KG

Stuttgart · New York

ISSN 0013-726X

\section{Corresponding author}

Anna Pietrzak, MD

Roentgen 5 Str.

02-781 Warsaw

Poland

Fax: +48-22-5463035

anpietrzak@gmail.com 